\title{
13 Learning Through Interactive Digital Narratives
}

\author{
Andreea Molnar and Patty Kostkova
}

\section{INTRODUCTION}

One of the most effective ways of conveying information and learning is through storytelling and narratives. Thus, naturally, narratives have generated great interest and are being incorporated into educational computer games. They are seen as a valuable support for learning, allowing players to "make sense of experience, organize knowledge, sparking problem-solving skills and increase motivation" (Hodhod, Cairns and Kudenko, 2011). The story can provide a context for learning (Kapp, 2012), and interaction allows the player to actively participate in the construction of the story, stimulates curiosity and imagination, and leads to unintentional learning (Hodhod, Cairns and Kudenko, 2011). Inte- grating the narratives in the context of a computer game is seen by some authors as one of the elements that could determine the success or failure of a game (Göbel et al., 2009). In educational games, this adds another layer of complexity. The successful integration of educational content into the ludic component could determine its motivational nature (Padilla- Zea et al., 2014) and predict the students' engagement with the game. Narratives in an educational game are considered especially important for games aimed at children because their attention span is short and the games must keep them engaged while they are playing and learning (Padilla-Zea et al., 2014). It also shows how games could help teenagers improve their cognitive skills (Gaeta et al., 2014). This chapter aims to explore the research undertaken to integrate educational content into games that make use of narratives. We then examine how a predefined set of Learning Objectives (LOs) are integrated into an interactive detec- tive story using the Storytelling for educAtional inteRventions (STAR) framework, and we present the results of evaluating explicit knowledge acquisition (Rowley, 2007) through the gameplay of the Global Hamd- washing Day (GHD) game.

The rest of this chapter is organised as follows. First, a review of the existing approaches to integrating interactive narratives in educational games is presented. Then, we describe our approach to integrating the educational content in an interactive digital narrative (IDN) game. This will be followed by an evaluation of the game, as well as some concluding remarks. 


\section{EDUCATIONAL CONTENT INTEGRATION IN THE EDUCATIONAL GAME STORY}

Storytelling in educational games is used as a method for improving students' motivation and is considered an important component of learning (Padilla-Zea et al., 2014). One way educational storytelling can be used to motivate students is as a reward, where parts of the story are only shown to the player as a result of overcoming a challenge in the game (Bopp, 2008). Despite the potential of storytelling, most educational games have focused on simulations, thereby ignoring the actual storytelling aspect (Padilla-Zea et al., 2014). In order to motivate students, the challenge for games is to inte- grate the educational content into the ludic component of the game. Properly integrating the interaction methods in the story is of particular importance, as this can lead to the success or the failure of a game (Göbel et al., 2009).

Despite the recognised potential of educational games that make use of narratives (Gobel et al., 2009; Hodhod, Cairns and Kudenko, 2011; Molnar and Kostkova, 2013c; Padilla-Zea et al., 2014), very little research has been done on the integration of the educational content in the narrative of an educational game (Hodhod, Cairns and Kudenko, 2011; Molnar, Farrell and Kostkova, 2012; Padilla-Zea et al., 2014). According to Matthias Bopp (2008), a video game should define the game goal, divide the main goal into subgoals, and the subgoals should be related to the final goal of the game such that the player finds the task that provides her/him with a rewarding experience. Stefan Göbel et al. (2009) consider three elements essential in any educational game: learning, play and story, and they emphasise the importance of finding a balance between them. Their proposed scheme comprises of an introduction and a set of missions that act as game levels. Natalia Padilla-Zea et al. (2014) propose the division of the storytelling into scenes, sequences and chapters.

\section{STAR FRAMEWORK}

In our approach we used the Storytelling for educAtional inteRventions (STAR) framework (Molnar, Farrell and Kostkova, 2012). This framework (Figure 13.1) focuses on the level of the mission and proposes five characteris- tics of a successful interactive digital storytelling experience: an engaging story plot; conveying different sets of LOs and reinforcing the important ones; flex-ibility in adding or removing the LO; and having an interactive story and allow-ing the user to influence it. The story structure consists of an introduction, a set of puzzles, a resolution and a debriefing. The introduction will set the scene and define the problem. The set of puzzles consists of clues and red herrings that will either guide the player or move him away from the solution to the main puzzle. The next part is where the player finds the resolution, and hence the solution to the game/mission puzzle. The last part consists of a debriefing, a layer where the learning objectives are reinforced. Having this last part has facilitated the integration of the evaluation in the game (Molnar and Kostkova, 2013c). 


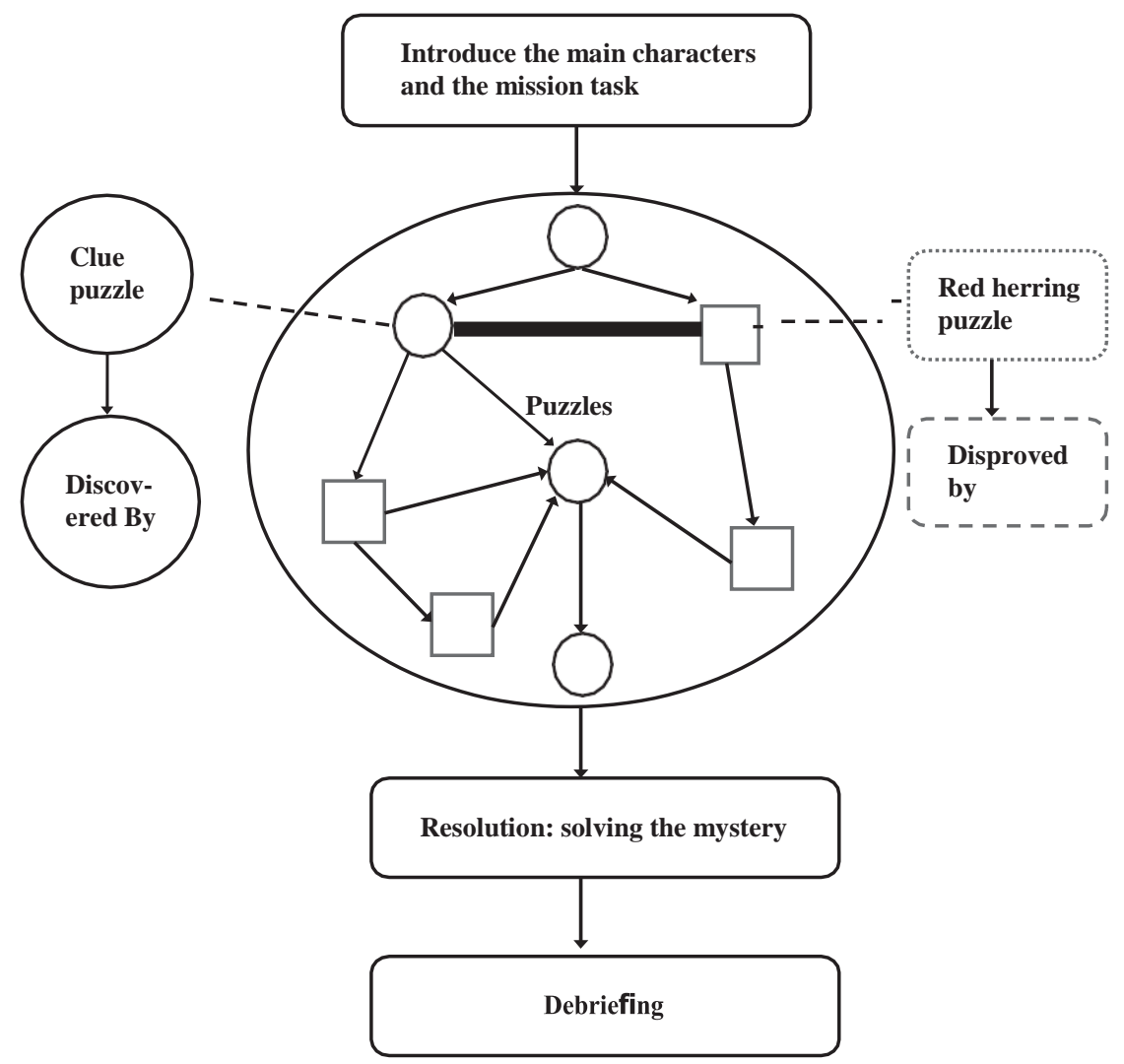

Figure 13.1 Story structure as described in the STAR framework (Molnar, Farrell and Kostkova, 2012).

From a pedagogical perspective, the STAR framework follows a problembased learning approach (Savery and Duffy, 1995). Also, in every mission, in order to solve the mystery the player has to recall knowledge, comprehend the situation, apply previous knowledge in a new situation, analyse a complex situation and break it out into parts, and synthesise and evaluate the information. These follow the six levels of Bloom's taxonomy (Bloom, 1974) and were initially outlined by Farrell et al. (2011a). Using this approach, several missions were created, as part of the Edugames4all project (Kostkova and Molnar, 2013), including the GHD game. The results of the GHD game evaluation are presented below.

\section{CASE STUDY}

The Edugames4all initiative (www.edugames4all.org) consists of a set of educational games aimed at increasing children's awareness of important health issues in an enjoyable manner. The games are aimed at children 
between the ages of 9 and 15 years. Two types of games were created: platform games (Molnar and Kostkova, 2013b) and interactive digital storytelling games (Molnar and Kostkova, 2013c). The latter consisted of five missions: one training mission that familiarised the players with the game mechanics (Molnar and Kostkova, 2013a) and another four missions dur- ing which the player became a detective who had to solve a mystery during which s/he learns about health issues (Molnar, Farrell and Kostkova, 2012). To solve the mystery, the player has to question possible guilty people (Figure 13.3), gather evidence and examine it, and draw and evaluate con- clusions based on such evidence. The games are created following the STAR framework described above and have the LOs integrated based on the European curriculum (Lecky et al., 2011), and their development with children in Europe was published by (Farrell, 2011b; de Quincey, 2011) and translated to 10 languages (Weerasinghe, 2010). The aim of the games is to have the children take the message home and lead to awareness about responsible hygiene and antibiotic use in the family (Lecky and McNulty, 2013).

We will expand on one of the missions, Global Handwashing Day Game (GHD Game), as this was used during this evaluation, but the other mis- sions follow a similar pattern by presenting a different mystery to be solved, along with different learning objectives. The plot of the game is as follows:

Introduction: First, the player is placed in the e-Bug/edugames4all agencyvand s/he is introduced to her/his boss, Big C (Figure 13.2). Also here, the player meets Alyx, who will be the player's partner and will help him/ her during the investigation. After the introductions are made, Big C pres- ents the problem. Hugh Gaego, a famous actor, is allegedly poisoned and the player has to decipher the mystery: whether it was a case of an alleged poisoning or not, and who the guilty party is, if any, for poisoning Hugh.

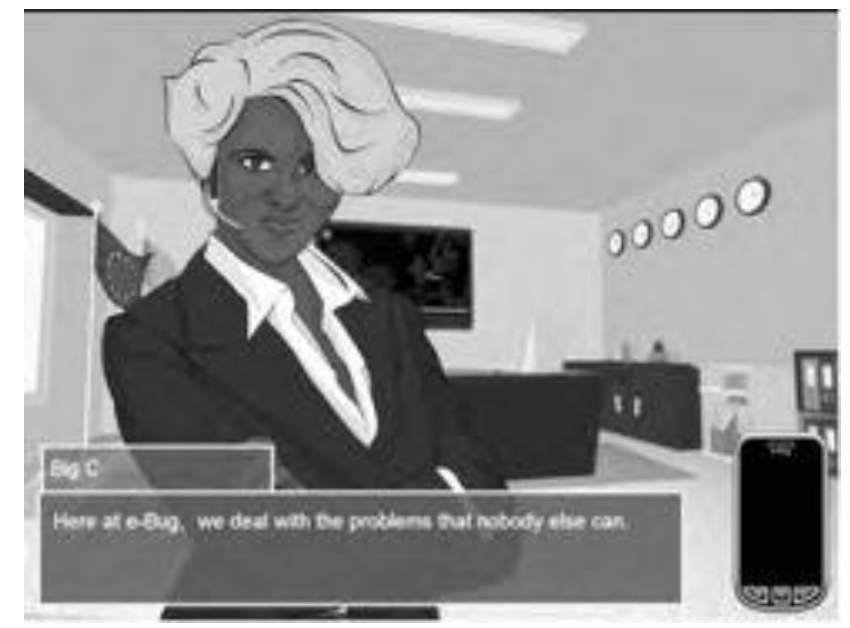

Figure 13.2 The player is welcomed to the agency. 
Puzzles: The state space of the game is quite vast, allowing players to explore different parts of the game. The game is nonlinear and allows differ- ent options during the investigation. Not all the paths lead to an answer and they are not all mandatory for solving the mystery. The clues should lead the player closer to solving the mystery whereas the red herrings should make the investigation more challenging.

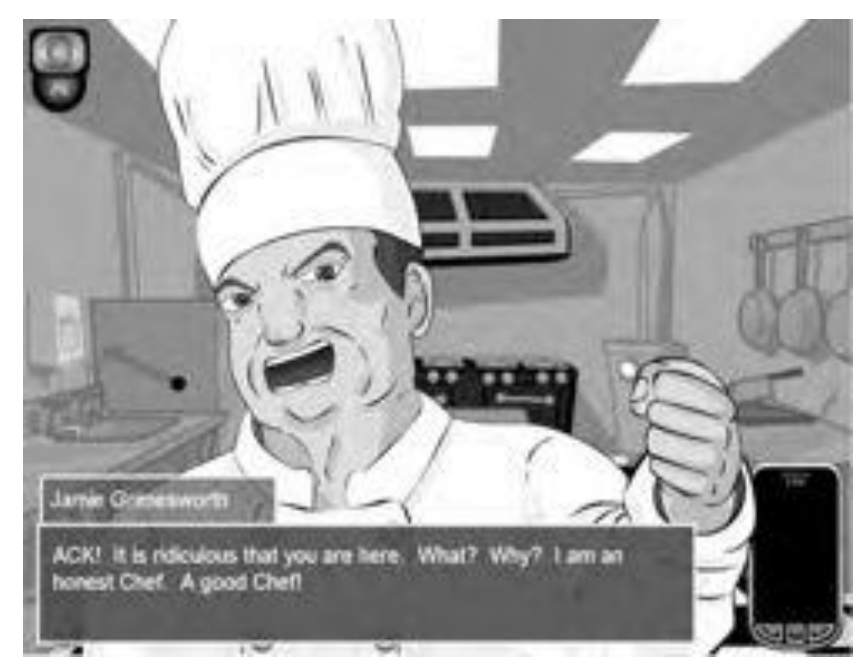

Figure 13.3 The player gathering evidence by talking with the witnesses.

During the investigation, Alyx is always ready to help the player by providing clues, asking questions related to the investigation and assisting with the evidence that was collected. There are six puzzles that integrate the learning objectives from this game, and they are described in detail in Molnar, Farrell and Kostkova's discussion (2012). The game also integrates the game flow questions (possible answers and feedback for assessing the learning objectives taught) (Molnar and Kostkova, 2013c). The questions are seamlessly integrated with most of the players not even noticing that they are evaluated (Molnar and Kostkova, 2013c). As a preknowledge and postknowledge test of the LOs integrated in the game is typically required to evaluate the game's effectiveness at delivering the educational content, the questions are asked at least two times during the game; they are asked once before the player is exposed to the game mechanics and narratives aimed at teaching a $\mathrm{LO}$ and once afterwards. Although the questions seamlessly integrated into the narrative flow, the evaluation is done by assessing the abstract and generalisable concepts within the game, as previous research has shown that some of the skills learned through games are not necessarily broad and general, and the player is able to use the skills in the same environment but has prob-lems translating them into a real-world environment (Bavelier et al., 2011). 
In order to reinforce the learning value of the game, we designed the LOs to be delivered both in an abstract manner and through fundamental game mechanics. There is a feedback mechanism integrated in the game in order to either reassure the player thathis/her answer is correct, or to correct misconceptions (e.g., a nonplayer character provides the player with the answer and explanation of why that is the correct option). The preevaluation is done through the puzzle section, and careful attention has been paid so that the player could be evaluated on all of the learning objectives before being exposed to them, regardless of the path $\mathrm{s} /$ he chooses to follow within the game.

Resolution: The resolution is reached when the player has solved the mystery (i.e., has found the guilty party for Hugh's poisoning-Figure 13.4).At this point the player has been exposed to all the learning objectives integrated in the game.

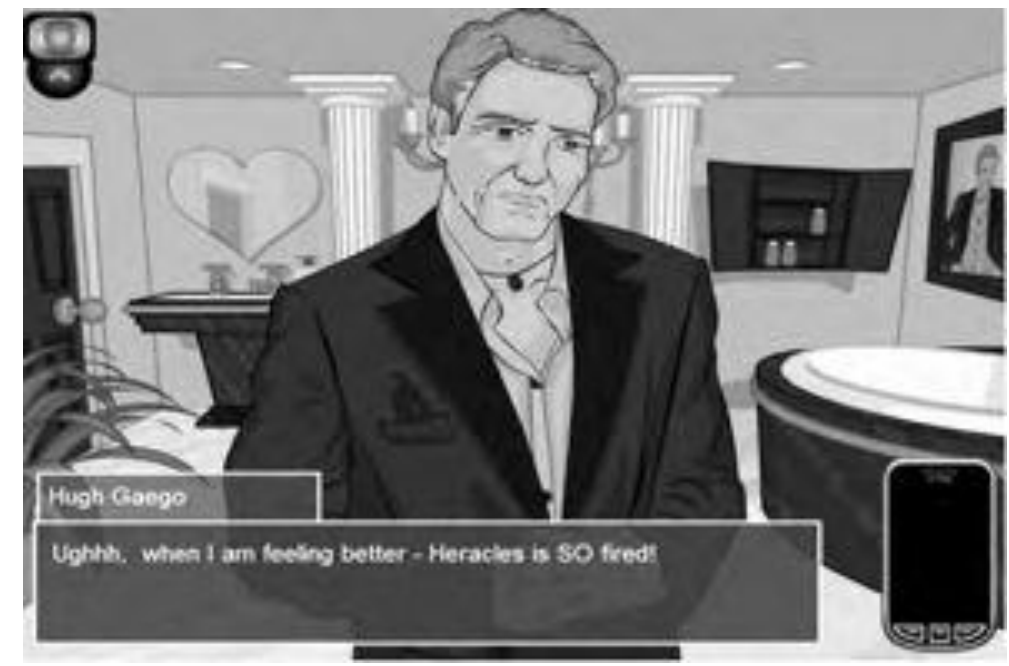

Figure 13.4 Hugh finds out that Heracles (his bodyguard) is the source of his illness.

Debriefing: After the investigation is over, the player returns to the agency for debriefing (Figure 13.5). Because we have a set of pregame and postgame questions to assess the knowledge before and after the LO is delivered, the second round of questions were asked during the debriefing. At the headquarters, Big $C$ asks the player the same set of questions and the player has to select among the same set of options as when the questions were asked for the first time. However, the player feels like s/he is reporting back to the boss rather than actually being asked the same initial questions during the game to seamlessly assess his/her knowledge update. This approach enables us to measure knowledge obtained in a manner that does not decrease the usability or enjoyment of the game (Kostkova, 2012; Molnar and Kostkova, 2013c). 


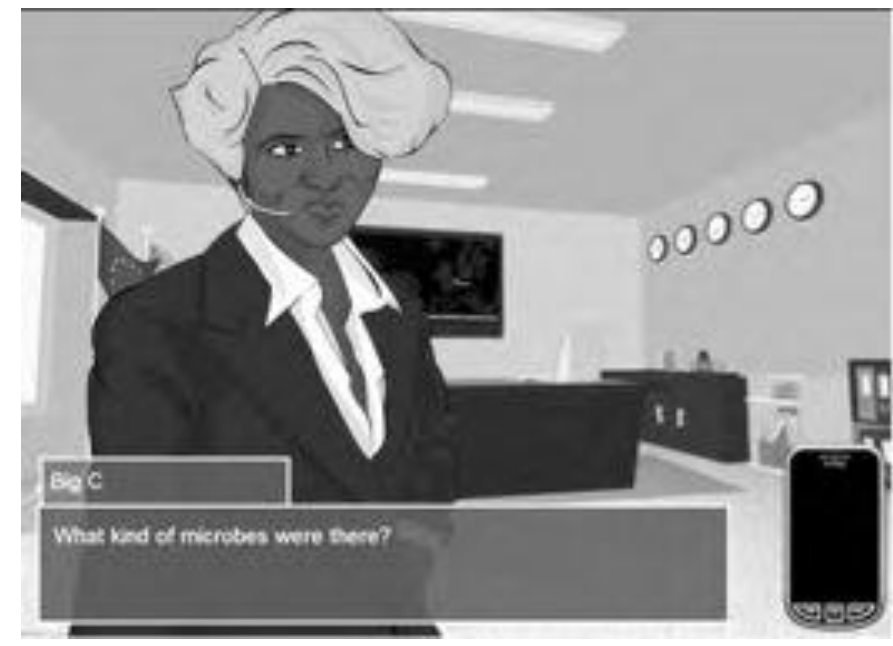

Figure 13.5 Debriefing-Big C asking questions about the investigation.

\section{EVALUATION}

We have performed an evaluation with school children demonstrating that the players did not feel that they were assessed through the game play, showing that the LOs and the evaluation were seamlessly embedded in the game story (Molnar and Kostkova, 2013c). The aim of the section is to expand upon the evaluation that was done to assess the effectiveness of the learning objectives integrated in the IDN of the GHD Game.

\subsection{Method}

The study took place either in a controlled environment or online at the participants' convenience. Children and teachers from two schools from London and Glasgow, UK, took part in the controlled environment study. All the participants were given incentives to participate in the study, such as vouchers or prizes that the children could earn by entering in a raffle. To measure the statistical significance of the effectiveness of the overall game in delivering the LOs, a paired ttest was used (Hsu and Lachenbruch, 2008), comparing the players' knowl- edge about the health issues before and after playing the game. To assess the statistical significance of the effectiveness of the game in delivering each of the LOs included in the game, we used the McNemar test because the answers for the questions used to assess the LOs were nominal (Eliasziw and Donner, 1991).

\subsection{Participants}

First, the participants were asked to complete a questionnaire through which demographic data was collected, and afterwards to play the game. The questionnaire was online and was displayed immediately before the game started loading. Completing the questionnaire was not mandatory (the participants 
could skip directly to the game) and the participants could at any time give up playing the game. The people who did not take part in a controlled environment study were mostly people who found the game online. The website containing the questionnaire and the games were relaunched in October 2011, and it was promoted during the Global Handwashing Day (15 October 2011) as well as through mailing lists. Most of the traffic recorded by the website was from English-speaking countries-UK ( 60\%), US $(\sim 10 \%)$, Ireland $(\sim 9 \%)$ - probably due to the fact that at that time only the English version of the games was posted online despite website traffic having come from 73 countries. A total of 145 participants were considered for the evaluation. As the evaluation is integrated in the game and the postknowledge evaluation is done just at the end of the game, the participants were selected based on whether they finished the game or not. Having participants that did not finalise the game would imply not having the results of the evaluation.

\subsection{Results}

Eleven LOs were assessed, as described in Table 1. The effectiveness of the game at conveying the educational content was performed using a paired ttest (Hsu and Lachenbruch, 2008) on the number of correct answers the players had given for the questions asked before and after playing. The results show that the difference between the players' pregame and postgame answers to the questions assessing the LOs is statistically significant ( $p$ $=0.01, C J=2.20$ ) when a 99 percent confidence interval is considered. The average number of correct answers to the pre-questionnaire was 7.8 , while the average score to the post-questionnaire was 8.8 . This result shows that the game is an effective way of conveying learning outcomes.

In order to assess whether each LO was efficiently conveyed, we used the McNemar test (Eliasziw and Donner, 1991). The results of the pre- and postquestionnaire evaluation for each of the LOs were analysed. A 95 percent confidence interval was considered statistically significant. The results of the analysis are presented in Table 13.1. The first column shows the LO that the row addresses. The second column presents the number of answers that were right $(\mathrm{R})$ both during the pre- and post-evaluation questionnaires, meaning that the player knew the answer before and after playing the game. The third column displays the answers that were answered wrong twice (W), meaning that the player did not know the answer previously to playing or afterwards. The fourth column shows the answers that changed from wrong to right, meaning that the player did not know the answer before playing, but s/he knew it after the game playing session. The fifth column presents the case when the player initially answered the question correctly, but after the game playing session the answer s/he gave was incorrect. The sixth column is the chi squared obtained as a result of the McNemar test, and in the last column we have the p value. For the LOs written with italics in the table (LO-1, LO-2, LO-4, LO-5, LO-8 and L0-9), the players' knowledge between the post-test and pre-test on that LO had significantly changed. Therefore, the narrative was more effective at delivering certain LOs than others. 
Table 13.1 McNemar test results on the players' answers to the Pre and Post LOs evaluation.

\begin{tabular}{|c|c|c|c|c|c|c|}
\hline$L O$ & $R \& R^{1}$ & $W \& W^{2}$ & $W \& R^{3}$ & $R \& W^{4}$ & $X^{2}$ & $p$ \\
\hline $\begin{array}{l}\text { LO-1: Microbes found in } \\
\text { food can transfer to humans }\end{array}$ & 109 & 6 & 8 & 22 & 7.01 & 0.01 \\
\hline $\begin{array}{l}\text { LO-2: Separate utensils } \\
\text { should be used for raw } \\
\text { meat and vegetables }\end{array}$ & 97 & 6 & 14 & 28 & 5.00 & 0.03 \\
\hline $\begin{array}{l}\text { LO-3: Bacteria from raw } \\
\text { meat can make a person sick }\end{array}$ & 103 & 6 & 19 & 16 & 0.18 & 0.67 \\
\hline $\begin{array}{l}\text { LO-4: Food cooked } \\
\text { properly should be free of } \\
\text { bacteria }\end{array}$ & 59 & 7 & 61 & 10 & 35.92 & 0.01 \\
\hline $\begin{array}{l}\text { LO-5: Vomiting viruses } \\
\text { are unpleasant but usually } \\
\text { not dangerous }\end{array}$ & 47 & 15 & 60 & 16 & 24.90 & 0.01 \\
\hline $\begin{array}{l}\text { LO-6: Vomiting viruses can } \\
\text { spread through sneezing, } \\
\text { coughing or just particles } \\
\text { of vomit that are in the air } \\
\text { after someone is sick }\end{array}$ & 67 & 22 & 39 & 31 & 0.80 & 0.37 \\
\hline $\begin{array}{l}\text { LO-7: Vomiting viruses } \\
\text { and E. coli can spread } \\
\text { through bad hygiene }\end{array}$ & 111 & 8 & 16 & 14 & 0.08 & 0.78 \\
\hline $\begin{array}{l}\text { LO-8: It is not always } \\
\text { necessary to take medicine } \\
\text { when dealing with E. } \\
\text { coli and vomiting viruses } \\
\text { infections }\end{array}$ & 60 & 4 & 36 & 20 & 4.29 & 0.04 \\
\hline $\begin{array}{l}\text { LO-9: E.coli is commonly } \\
\text { found in the lower intestine }\end{array}$ & 74 & 29 & 40 & 11 & 15.93 & 0.01 \\
\hline $\begin{array}{l}\text { LO-10: E.coli can spread } \\
\text { through the 'faecal- } \\
\text { oral' route or poor food } \\
\text { preparation hygiene }\end{array}$ & 95 & 20 & 30 & 18 & 2.76 & 0.10 \\
\hline $\begin{array}{l}\text { LO-11: If eaten, bacteria } \\
\text { from raw meat can make a } \\
\text { person sick }\end{array}$ & 102 & 2 & 22 & 14 & 1.57 & 0.21 \\
\hline
\end{tabular}

Italic text was used to highlight the LOs for which statistical significant difference was obtained between the player knowledge before and after playing the game.

${ }^{1} \mathrm{R} \& \mathrm{R}$ - the numbers of player that provided a right answer for the given LO before and after playing the game.

${ }^{2} \mathrm{~W} \& \mathrm{~W}$ - the number of players that provided a wrong answer for the given LO before and after playing the game.

${ }^{3} \mathrm{~W} \& \mathrm{R}$ - the number of players that provided a wrong answer for the given LO before playing the game and a right answer for the given LO after playing the game.

${ }^{4} \mathrm{R} \& \mathrm{~W}$ - the number of players that provided a right answer for the given LO before playing the game and a wrong answer for the given LO after playing the game. 


\section{CONCLUSION}

Although narratives and storytelling are well known methods through which information is conveyed, little research has been done on how to integrate educational content into the narratives of games. The STAR frame- work proposes to have a sequence of puzzle and red herrings during which LOs are taught (Molnar, Farrell and Kostkova, 2012). Different paths are allowed through the game and the player is free to explore them, but regard- less of the path, the player has to cover the core of the LOs aimed to be taught. Evaluation could be seamlessly integrated into the game narratives (Molnar and Kostkova, 2013c). Based on the STAR framework, a game (GHD Game) was implemented. The efficiency of the game in delivering the LOs was assessed with 145 participants. The results showed that the students learned as a result of the game play; however, the players' learning achievements are not evenly distributed across all the LOs.

\section{REFERENCES}

Bavelier, D., Green, C. S., Han, D. H., Renshaw, P.F., Merzenich, M. M., and Gentile, A. A. (2011), 'Brains on video games.' Nature Reviews Neuroscience. 12. pp. 763-768.

Bloom, B. S. (1974) Taxonomy of Educational Objectives: The Classification of Educational Goals. Handbook 1-2. Longmans: McKay.

Bopp, M. M. (2008) Storytelling and motivation in serious games. In: Final Consolidated Research Report of the Enhanced Learning Experience and Knowledge Transfer-Project (ELEKTRA, http://www.elektra-project.org/), a project supported by the European Commission (nr. 027986).

de Quincey, E., Kostkova, P.,Jawaheer, G., Farrell, D., McNulty, C.A. M., Weinberg, J., Goossens, H., Adriaenssens, N., De Corte, S., Holt, J., Noer, M., Kremastinou, J., Merakou, K., Gennimata, D., Cornaglia, G., Koncan, R., Grzesiowski, P., Olczak-Pienkowska, A., Brito Avo, A., and Campos, J. (2011) Evaluating the online activity of users of the e-Bug web site. Journal of Antimicrobial Chemotherapy. 66(44-49, suppl 5).

Eliasziw, M. and Donner, A. (1991) Application of the McNemar test to nonindependent matched pair data. Statistics in Medicine. 10(12). pp. 1981-1991.

Farrell, D., Kostkova, P., Lazareck, L., Weerasinghe, D., Weinberg, J., Lecky, D. M., Adriaenssens, N., Herotová, T. K., Holt, J., Touboul, P., Merakou, K., Koncan, R., Olczak-Pienkowska, A., Avô, A. B., Campos, J., Cliodna A. M., and McNulty, C. A. (2011a) Developing e-Bug web games to teach microbiology. Journal of Antimicrobial Chemotherapy. 66(33-38, suppl 5), v33-v38.

Farrell, D., Kostkova, P., Weinberg, J., Lazareck, L., Weerasinghe, D., Lecky, D. M., and McNulty, C. A. M. (2011b) Computer games to teach hygiene: an evaluation of the e-Bug junior game. Journal of Antimicrobial Chemotherapy. Vol. 66. suppl 5. v39-v44.

Gaeta, M., Loia, V., Mangione, G. R., Orciuoli, F., Ritrovato, P., and Salerno, S. (2014) A methodology and an authoring tool for creating Complex Learning Objects to supportinteractive storytelling. Computersin Human Behaviour.31.pp.620-637. 
Göbel, S., de Carvalho Rodrigues, A., Mehm, F., and Steinmetz, R. (2009) Narrative game-based learning objects for story-based digital educational games narrative. Narrative. 14. p. 16.

Hodhod, R., Cairns, P., and Kudenko, D. (2011) Innovative integrated architecture for educational games: challenges and merits. Transactions on Edutainment. 5. pp. 1-34.

Hsu, H. and Lachenbruch, P. A. (2008) Paired t Test. Wiley Encyclopedia of Clinical Trials.

Kapp, K. M. (2012) The Gamification of Learning and Instruction: Game-based Methods and Strategies for Training and Education. New Jersey: Wiley.

Kostkova, P. (2012) Seamless Evaluation of Interactive Digital Storytelling Games: Edugames4All, P. Kostkova, M. Szomszor, and D. Fowler (Eds.): eHealth 2011, Springer Lecture Notes of the Institute for Computer Sciences, Social-Informatics and Telecommunications Engineering LNICST 91, pp. 80-84.

Kostkova, P.and Molnar, A. (2013) Edugames4all: Computer games teaching children abstracts about bugs and drugs. In IPNET-Kenya/ICAN Joint Conference, 68 November, Mombasa, Kenya.

Lecky, D. M., McNulty,A. M. C.,Adriaenssens, N., Herotov,T. K., Holt, J., Touboul, P., Merakou, K., Koncan, R., Olczak-Pienkowska, A., Avo, A. B., Campos, J., Farrell, D, Kostkova, P., and Weinberg, J. (2011) What are school children in Europe being taught about hygiene and antibiotic use? Journal of Antimicrobial Chemotherapy. 66(13-21, suppl 5).

Lecky, D. M. and McNulty, C. A. (2013) Current initiatives to improve prudent antibiotic use amongst school-aged children. Journal of Antimicrobial Chemotherapy. 68(11). pp. 2428-2430.

Molnar, A., Farrell, D., and Kostkova, P. (2012) Who poisoned Hugh?-the STAR framework: Integratinglearning objectives with storytelling. In: Oyarzun, D.,Peinado, F., Young, R. M., Elizalde, A., and Méndez, G. (eds.) Fifth International Conference on Interactive Digital Storytelling (ICIDS). LNCS, 7648. Berlin, Heidelberg: Springer.

Molnar, A. and Kostkova, P. (2013a) If you build it would they play? Challenges and solutions in adopting health games for children. In ACM SIGCHI Conference on Human Factors in Computing Systems.

Molnar, A. and Kostkova, P.(2013b) On effective integration of educational content in serious games. In 13th IEEE International Conference on Advanced Learning Technologies, Beijing, China.

Molnar, A. and Kostkova, P.(2013c) Seamless evaluation integration into IDS educational games. In Foundations of Digital Games, Chania, Greece.

Padilla-Zea,N.,Gutierrez,F.L.,Lopez-Arcos,J.R.,Abad-Arranz, A., and Paderewski, P. (2014) Modelling storytelling to be used in educational video games. Computers in Human Behaviour. 31(1). pp. 461-474.

Padilla-Zea, N., Sánchez, J. L. G.,Vela, F.L. G.,Abad-Arranz,A., and Lopez-Arcos, J. R. (2012) Evaluating emotions in educational videogames: The particular case of children. In 13th International Conference on Interacción Persona-Ordenador.

Rowley, J. (2007) The wisdom hierarchy: Representations of the DIKW hierarchy. Journal of Information Science. 33(2). pp. 163-180.

Savery, J. R. and Duffy, T. M. (1995) Problem based learning: An instructional model and its constructivist framework. Educational Technology. 35(5). pp. 31-38.

Weerasinghe D., Lazareck L., Kostkova P., and Farrell D. (2010) Evaluation of popularity of multi-lingual educational web games-Do all children speak English? eHealth. 2(23). pp. 44-53. 